\title{
Professional and patient attitudes to using mobile phone technology to monitor asthma: questionnaire survey
}

\author{
Hilary Pinnock ${ }^{a, *}$, Roger Slack ${ }^{b}$, Claudia Pagliari $^{a}$, \\ David Price ${ }^{c}$, Aziz Sheikh ${ }^{a}$
}

a Division of Community Health Sciences: GP Section, University of Edinburgh, 20 West Richmond St, Edinburgh EH8 9DX, UK

b School of Informatics, University of Edinburgh, 1 Buccleuch Place, Edinburgh EH8 9LW, UK

c Department of General Practice and Primary Care, Foresterhill Health Centre, Westburn Road, Aberdeen AB25 2AY, UK

Received 14 March 2006; accepted 27 March 2006

\section{KEYWORDS \\ Asthma; \\ Mobile techriolog); \\ Monitoring}

\section{surnmary}

Aims: There is increasing interrlational interest in using emerging technologies to

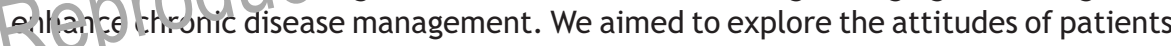
and primary care professionals to using mobile technology in order to monitor asthma.

Methods: A piloted questionnaire containing closed and open-ended questions assessing attitudes to using electronic self-monitoring was posted to a random sample of general practitioners, asthma nurses, and people with asthma (12 years and over) in Lothian and Kent, UK, with 2 reminders. In addition to descriptive statistics, patient and clinician responses were compared using Chi-squared or independent sample t-tests. Free-text responses were analysed thematically.

Results: Responses were obtained from 130/300 professionals (43\%) and 202/389 patients $(52 \%)$. Patients rated the technology positively and considered that it may help clinicians to provide care, especially during acute attacks. Although rated similarly, professionals were more sceptical about benefits. Both professionals and patients had concerns about the time and cost implications. Of the respondents, 28 professionals $(10 \%)$ and 62 patients $(16 \%)$ returned uncompleted questionnaires citing lack of perceived relevance.

Conclusions: The low completion rate probably reflects the current status of mobile phone-facilitated care as a minority interest for 'early adopters' of technology. Even for the enthusiastic minority, using mobile phone technology raised questions of

\footnotetext{
* Corresponding author. Tel.: +44 (0) 131651 4151; fax: +44 (0) 1316509119.

E-mail address: hilary.pinnock@ed.ac.uk (H. Pinnock).
} 
clinical benefit, impact on self-management, and concerns about workload and cost, which will need to be addressed prior to wider acceptance.

(c) 2006 General Practice Airways Group. Published by Elsevier Ltd. All rights reserved.

\section{Introduction}

Modern forms of communication offer considerable potential for enhancing medical care [1-3], particularly in ensuring timely access to emergency advice [4,5], and in the management of chronic disease $[6,7]$. Mobile phones are now widely available [8], and offer innovative opportunities for messaging which have been used to remind patients of appointments [9] and to encourage compliance with inhaled steroids in asthma [10].

Guided by written asthma action plans, some patients accept the responsibility for monitoring and adjusting their own treatment [11], whilst others fail to respond to cues for self-management $[12,13]$ and delay important actions pending the advice of a clinician [14-17]. Novel technologies may change the dynamics of monitoring and care. For example, linking an electronic peak flow meter with a mobile phone has been successfully piloted in teenagers and younger adults with asthma, improving compliance with monitoring, and improving confidence in self-management [13].

Widespread uptake, however dspe: ds on professionals' and pitient' $\checkmark$ aititudes to the potentiat benefits | as well as the user-friendlinets. and clinica! cpp opriatene:s on the sustem. The recognised life-cycle of technology adoption (see Figure 1) suggests there will be 'innovators' and 'early adopters' who will welcome the technology, readily identifying clinical situations in which they may benefit [19]. Others will be more sceptical, expressing practical concerns or feeling uncomfortable with unfamiliar systems. Identifying current perceptions, and the perceived barriers to more extensive adoption, is a prerequisite for breaching the 'chasm' and enabling new ideas to be placed appropriately within a primary care service [20].

Our survey aimed to explore the attitudes of patients and primary care professionals to using mobile technology in order to monitor their asthma, and to assess the potential impact on their asthma management.

\section{Methods}

The survey was conducted in 2005, in Lothian and Kent, UK, with the approval of the Multi Centre Research Ethics Committee for Scotland.
Governance approval was granted by NHS Lothian and Kent Primary Care Trusts.

\section{Setting}

Lothian (Central Scotland) and Kent (South East England) include both city and rural environments and represent populations with a diversity of demographic features including areas of deprivation/affluence.

\section{Questionnaire design [21]}

We devised a structured questionnaire, adapted for doctors, nurses or people with asthma, including a brief description of an asthma monitoring service which enables electronic peak flow readings to be transmitted to a central server which feeds back information on current control and reminders on self-management [E-san Ltd, Oxford, UK: mmO2, Uxbridge, UK]. The question laite asked about attitudes to such in ioverive echnology, focusing op its acceptabilicy, practicability and impact on Gare (see associated with this article, located, in the 6 line/Version, at Supplementary data doi: $10.1016 / j . p c r j .2006 .03 .001)$. Designed by a multidisciplinary team, our questions were based on a detailed review of the literature on the use of mobile technology to monitor chronic disease [1-3], the process of adoption of new technologies [20], and the concepts of asthma self-management [15-17]. Minor adjustments were made after initial piloting.

The relative importance of potential issues was assessed by asking respondents to rate their agreement with statements on a 5-point Likertscale [ $1=$ strongly agree; $5=$ strongly disagree], or to choose between two opposing positions on a scale of 1 to 10 . Where appropriate, similar questions were devised for patients and professionals to allow for comparison. Closed questions included an option for adding additional comments in free-text, and a final open question invited more general opinions.

\section{Administration of the questionnaire [22]}

We sent the questionnaire to a random sample of 150 general practitioners (GPs) and 'the asthma nurse' of 150 randomly selected practices in Lothian and Kent. We phoned non-responding practices to check receipt of the mailing, and 


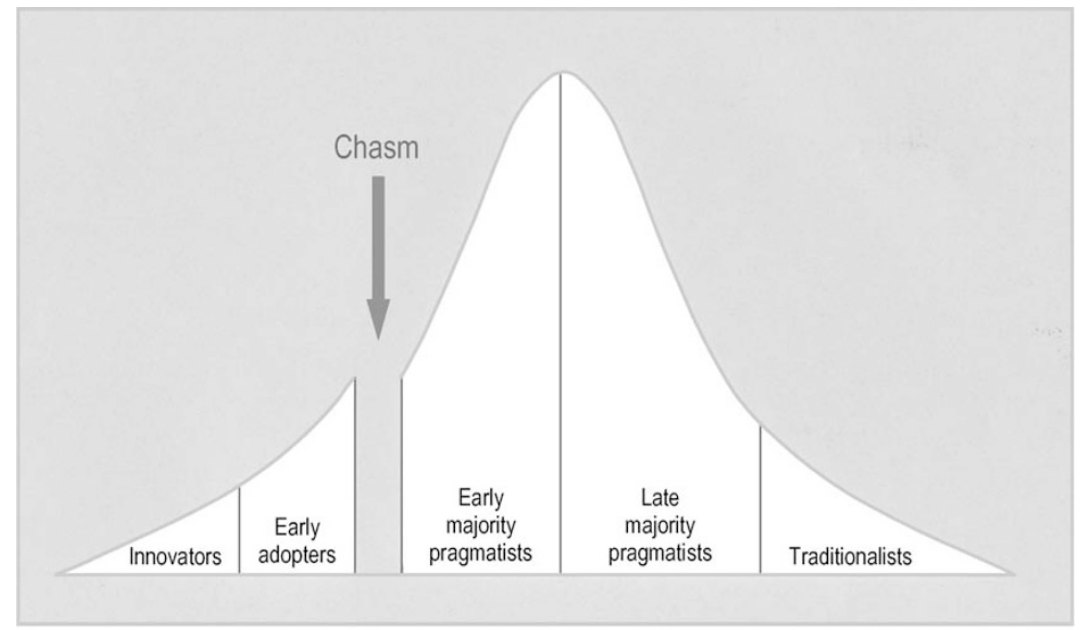

\begin{tabular}{|c|c|}
\hline & Attributes \\
\hline Innovators & Enthusiasts who adopt new technology because it is novel \\
\hline Early Adopters & $\begin{array}{l}\text { Those who have the vision to adopt an emerging technology because it } \\
\text { allows them achieve something novel, and to address an issue that is } \\
\text { important to them }\end{array}$ \\
\hline \multicolumn{2}{|c|}{$\begin{array}{l}\text { The Chasm } \\
\text { Time gap in technology adoption, between the early adoptors and the pragmatists. }\end{array}$} \\
\hline $\begin{array}{l}\text { Early Majority } \\
\text { Pragmatists }\end{array}$ & $\begin{array}{l}\text { Solid citizens who do not like to take the risks of pioneering, but are ready to } \\
\text { see the advantages of tested technologies. They are the beginning of a } \\
\text { mass market }\end{array}$ \\
\hline $\begin{array}{l}\text { Late Majority } \\
\text { Pragmatists }\end{array}$ & $\begin{array}{l}\text { Traditionalists who are sceptical of progress. They buy high-technology } \\
\text { products reluctantly, perhaps driven by necessity, but they do not expectt to } \\
\text { like them. }\end{array}$ \\
\hline Traditionalists & 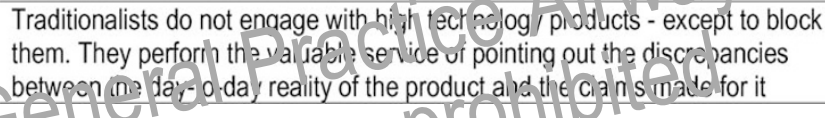 \\
\hline
\end{tabular}

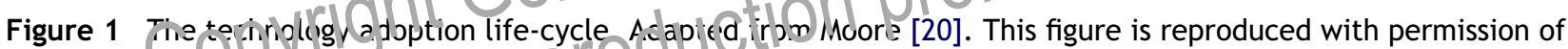
John Wiley \& sens Ltd on behalf of cids sor e Publisining Ltd.

offered an electronic version of the questionnaire if preferred. Two reminders were sent to non-responders.

Three Lothian and three Kent practices identified adults and teenagers with 'active asthma' (definition: aged 12 years and over; on the practice asthma register; and having received a prescription for asthma therapy in the previous 12 months) registered with a randomly selected GP. Two reminders were sent to non-responders.

We provided an option for both patients and professionals to indicate that they felt the topic was of no interest to them, and for them to return an uncompleted questionnaire.

\section{Data analysis}

Categorical and continuous data were analysed appropriately depending on type and distribution of data using SPSS version 11.5. A mean technology score was calculated by combining the scores from the four questions assessing general attitude to technology. In addition to descriptive statistics, patient and clinician responses were compared using Chi-squared or independent sample t-tests.

A multidisciplinary group analysed free-text responses by developing a coding frame and identifying key emerging themes [22-23].

\section{Results}

We received responses from $66 / 150$ GPs (44\%), $64 / 150$ nurses (42\%), and 202/389 patients (52\%). Of the respondents, 20 GPs $(13 \%)$, nine nurses (6\%) and 62 patients $(16 \%)$ indicated that they felt the questionnaire was of no relevance or of no interest to them, some adding free-text comments to explain their decision not to complete the questionnaire. The 140/389 (36\%) patients who returned completed questionnaires had a similar demographic profile (mean age 44.0 years (SD 18.5), $39 \%$ male) to the eligible sample (mean age 43.1 years (SD 19.5) $42 \%$ male). The $46 / 150$ GPs (31\%) and 55/150 nurses (36\%) who returned 
Table 1 Demography of respondents

\begin{tabular}{|c|c|c|c|c|}
\hline & \multicolumn{2}{|l|}{ Doctors } & \multicolumn{2}{|l|}{ Nurses } \\
\hline Total number of GPs/practices & GPs: 896 & & Practices: 222 & \\
\hline Randomly selected & 150 & Male: $79 / 139$ (53\%) & 150 & Not known \\
\hline Responded & $66(44 \%)$ & & $64(42 \%)$ & \\
\hline Completed questionnaires & $46(31 \%)$ & Male: 22 (48\%) & $55(36 \%)$ & Male: 4/54 (7\%) \\
\hline \multicolumn{5}{|l|}{ Age groups } \\
\hline 20 to 29 years & 1 & & 0 & \\
\hline 30 to 39 years & 9 & & 8 & \\
\hline 40 to 49 years & 22 & & 25 & \\
\hline 50 to 59 years & 14 & & 19 & \\
\hline over 60 years & 0 & & 3 & \\
\hline \multicolumn{5}{|l|}{ Practice demography } \\
\hline Mean list size (SD) & 8,735 (SD & 09) & 7,327 (SD 3,962) & \\
\hline Inner city & $3(7 \%)$ & & $10(18 \%)$ & \\
\hline Urban & $34(74 \%)$ & & $28(51 \%)$ & \\
\hline Rural & $9(20 \%)$ & & $11(20 \%)$ & \\
\hline Remote & 0 & & 0 & \\
\hline Deprived & $4(9 \%)$ & & $7(13 \%)$ & \\
\hline \multicolumn{5}{|l|}{ Role in asthma care } \\
\hline Interest in asthma? & $14(32 \%)$ & & $50(91 \%)$ & \\
\hline See asthma patients & 31 (67\%) & & (Has asthma dipl & oma) 44 (80\%) \\
\hline Rarely see asthma patients & 0 & & 0 & \\
\hline \multicolumn{5}{|l|}{ Specialist roles } \\
\hline \multicolumn{5}{|l|}{ G/P with Special Interest } \\
\hline \multirow{2}{*}{\multicolumn{5}{|c|}{$\begin{array}{l}\text { Member speclatist society: } \\
\text { Advisor Primary Care Organisation: }\end{array}$}} \\
\hline & & & & \\
\hline \multicolumn{5}{|l|}{ Practice Q\&O lead: } \\
\hline & & Number (\%) & Mean age (SD) & Male (\%) \\
\hline \multicolumn{5}{|c|}{$\begin{array}{ll}\text { Total eligible population: from } 6 \text { practices. } & 408\end{array}$} \\
\hline \multicolumn{2}{|c|}{ Excluded by GP } & 19 & & \\
\hline \multicolumn{2}{|l|}{ Total sent questionnaires } & 389 & $43.1(19.5)$ & $163(42 \%)$ \\
\hline \multicolumn{2}{|l|}{ Responded } & $202(52 \%)$ & & \\
\hline \multicolumn{2}{|l|}{ Completed questionnaires } & $140 / 389(36 \%)$ & $44.0(18.5)$ & $54(39 \%)$ \\
\hline \multicolumn{5}{|l|}{ Current asthma treatment } \\
\hline \multicolumn{2}{|l|}{ None } & $2 / 140(1 \%)$ & & \\
\hline \multicolumn{2}{|l|}{ Reliever (blue inhaler) } & $116 / 140(83 \%)$ & & \\
\hline \multicolumn{2}{|l|}{ Preventer (brown/orange/maroon) } & $86 / 140(61 \%)$ & & \\
\hline \multicolumn{2}{|l|}{ Add on (green inhaler or tablets) } & $21 / 140(15 \%)$ & & \\
\hline \multicolumn{2}{|l|}{ Combination inhaler (purple/red) } & $38 / 140(27 \%)$ & & \\
\hline \multicolumn{2}{|l|}{ Other } & $17 / 140(12 \%)$ & & \\
\hline
\end{tabular}

completed questionnaires worked in a broad range of practices (see Table 1). Nurse and GP responses to all the questions were similar and were therefore combined as 'professional' responses.

\section{Current attitudes to peak flow charting and self-management}

Home peak flow monitoring is widely encouraged with $84 / 101$ professionals $(84 \%)$ routinely prescribing peak flow meters for adults with asthma, and $98 / 140$ patients $(70 \%)$ agreeing that they had a peak flow meter at home, though only $22 / 91$ of these patients kept a record of their peak flows.

Professionals were positive about encouraging self-management, scoring their agreement with the statement 'I would like most of my asthma patients to have a written self-management plan' at 1.9 (SD 0.8 ) By contrast, patients were undecided about 
Table 2 Attitudes to technology

\begin{tabular}{lllll}
\hline Variable & $\begin{array}{l}\text { Patients } \\
\text { mean (SD) }\end{array}$ & $\begin{array}{l}\text { Professionals } \\
\text { mean (SD) }\end{array}$ & Mean difference & $p$ \\
\hline Mean overall technology score & $7.1(2.4)$ & $6.9(1.8)$ & $-0.3(95 \% \mathrm{Cl}-0.8$ to 0.3$)$ & 0.38 \\
Trying out new technology & $7.2(2.7)$ & $6.8(1.9)$ & $-0.4(95 \% \mathrm{Cl}-1.0$ to 0.3$)$ & 0.26 \\
Learning to use technology & $7.0(2.7)$ & $6.5(2.2)$ & $-0.6(95 \% \mathrm{Cl}-1.2$ to 0.$)$ & 0.09 \\
Exploring the potential of technology & $7.0(2.6)$ & $6.6(2.0)$ & $-0.4(95 \% \mathrm{Cl}-1.0$ to 0.3$)$ & 0.25 \\
Technology as part of life & $6.9(3.0)$ & $7.6(2.0)$ & $0.7(95 \% \mathrm{Cl} 0.0$ to 1.4$)$ & 0.05 \\
\hline
\end{tabular}

Scale of 1 to 10 (1 avoids technology, 10 embraces technology).

their preference for self-management, scoring a neutral 3.1 (SD 1.1) in agreement with the statement 'I prefer to look after my own asthma and would not want to bother my doctor or nurse'.

\section{Attitudes to technology in general}

Both patients and professionals were positive in their attitude to new technology with similar mean technology scores (professionals 6.9 (SD 1.8) vs. patients 7.1 (SD 2.4) mean difference $-0.3(95 \% \mathrm{Cl}$ -0.8 to 0.3$) p=0.38)$, though patients' attitudes to technology were more polarised than those of professionals. Responses to the individual questions are given in Table 2. Free-text comments confirmed the range of attitudes, from the very enthusiastic to those having no interest in communicition. technology.

"What a antuscididela!y' Patient $33 \mathrm{~F}$

"The technology is available. it mukes sense to use it." Patient $42 \mathrm{~F}$

"No mobile phone hard of hearing. No website or mobile phone not on internet."' Patient $74 \mathrm{M}$

Lack of technical expertise was one of the reasons given by patients who decided against completing the questionnaire.

"I am sorry I cannot be more helpful in answering the questionnaire I received recently, as I do not understand anything about modern technology." Patient $82 \mathrm{~F}$ who declined to complete the questionnaire.

\section{Attitudes to electronic peak flow monitoring}

Patients were keener than professionals to try the mobile technology with a positive mean score of 2.1 (SD 1.2) in agreement with the statement 'I would like to try out this monitoring technology' compared to the relatively neutral 2.8 (SD 1.1) scored by the professionals (mean difference 0.6 ( $95 \% \mathrm{Cl} 0.3$ to 0.9$), p<0.01)$.
The free-text comments reflect some patients' enthusiasm to try out new technology for themselves, compared to an (unsurprisingly) more academic interest on the part of the professionals.

"It would be very helpful to me and I would like to use it." Patient $14 \mathrm{~F}$

"I would really like to try out this new system especially if it helps with my asthma." Patient 33 $\mathrm{F}$

"Interesting concept: Are there papers on doing this in asthma/other already?' ' GP M (age not given)

\section{Implicacions for care}

Table 3 compadrest pinessional and patient scores to sta $\in$ ments about the implications of using mobile technology for monitoring asthma care. In general, patients thought that the monitoring technology would help their doctor or asthma nurse look after their asthma, especially in the event of an acute attack. Professionals, however, were more sceptical both in their scoring and free-text comments.

"I think the technology could save my life and that is a good thing." Patient $41 \mathrm{~F}$

"Excellent idea, I personally think this could help asthmatics and their doctors/nurses to prevent major asthma attacks." Patient $62 \mathrm{~F}$

"There are some others who don't care and do nothing when feeling fine and present in extremis and I suspect they will still do exactly that regardless." GP 30-39 F

"Would need to observe/have demo/read up literature/evidence etc before making any further decisions about benefits to patient care." Asthma nurse $40-49 \mathrm{~F}$

Opinions of both professionals and patients were divided on how the technology would impact on the professional/patient relationship-facilitating 


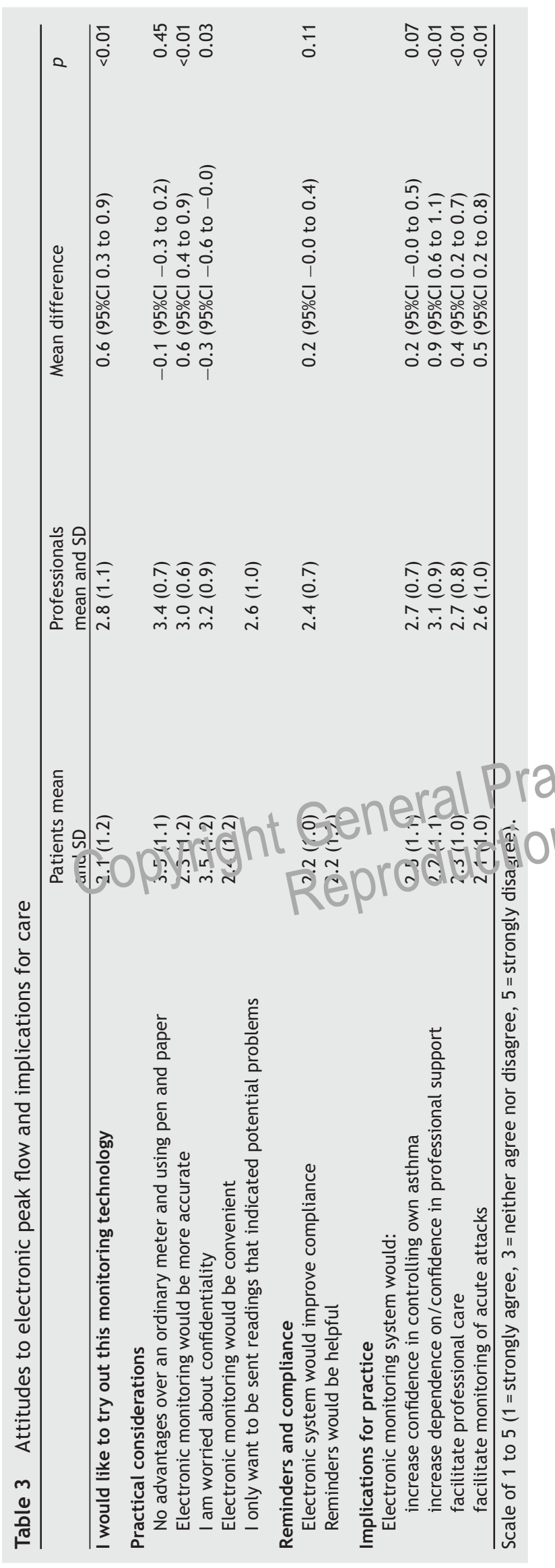

communication or reducing face-to-face contact, increasing dependence or facilitating selfmanagement. Confidentiality was not highlighted as a major issue by either group.

"I would not have to explain to my GP or Practice Nurse if they have this info on tap." Patient $71 \mathrm{~F}$

"I am very much in favour of trying any advances, technological or otherwise, but I am slightly worried that this proposed phone monitoring may lessen face-to-face contact between patient and doctor/nurse." Patient $62 \mathrm{~F}$

"I would like to have something that would not only monitor my peak flow but give me a warning when my breathing/asthma may be becoming a problem." Patient $24 \mathrm{~F}$

'By receiving patients' peak flow readings, I expect I would then be responsible for acting on them. This would be difficult to implement and take some responsibility from the patient to manage their own care." GP 50-59 M

"My main concern would be thia (p) aliphts feel we are interfring vity their cay to day lives and becrome ir icated." GP 30-39 F

One CR inaitioncened about the medico-legal imp icatiurs it he failed to act on readings that had been transmitted to his surgery.

"Places further burden of responsibility on clinician if results are forwarded to GP who fails to deal with them $\rightarrow$ litigation.' GP 40-49 F

\section{Practical issues}

Concerns about the time and cost implications were voiced by both professionals and patients in the free-text comments.

"This system would only be successful if doctor/nurse hours are allocated on a daily basis. My problem is that I don't think that this will happen. If there was complete buy-in by doctors/nurses then the system has a good chance." Patient $56 \mathrm{M}$

"I am not sure how this would work, who or how you would monitor incoming patient information, who would be responsible on a 24h, 365 day $a$ year?' ' Asthma nurse 50-59 F

"What additional charges are incurred when using this - is it chargeable to us?' ' Patient $26 \mathrm{~F}$ 


\section{Discussion}

Our questionnaire on using mobile technology to monitor asthma attracted the interest of about a third of patients and professionals. The idea was thus greeted with enthusiasm by a significant minority of the patients, considered with interest by some professionals, but raised a range of issues for both groups. In general, patients were optimistic about the potential benefits of the system for the care of their asthma, though they questioned who would meet the cost. Professionals were generally neutral about the impact on care and were concerned about workload implications. For some people, unfamiliarity with the technology was a significant barrier.

\section{Limitations of this study}

The completion rate of $35 \%$ is low and reduces generalisability, although responders had a similar demography to that of the eligible population, implying that our questionnaire had interested the enthusiasts across the full demographic range. The number of additional respondents who explicitly declined to complete the questionnaire because ot a lack of interest in technology, no avail atle oc dile phone or internet access, or a pereption that the

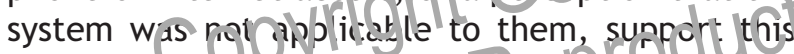
interpretation.

Answers to closed questions and free text responses can only provide limited insights into attitudes to the adoption of mobile technology. Information about the technology was restricted to a brief description of the monitoring system which may have influenced responses. Familiarity with both peak flow monitoring and mobile phone technology, however, will have reduced the possibility of significant misconceptions.

\section{Main strengths of this study}

The survey was undertaken in two areas of the UK, encompassing city, urban, and rural areas including a range of deprived and affluent populations. Our piloted questionnaire appeared to be acceptable to both patients and professionals and we identified no problems with completion. Integration of quantitative and qualitative analyses increases the validity of our findings [24], whilst the involvement of clinicians and social scientists enabled multidisciplinary interpretation of the findings.

\section{Interpretation of findings in relation to previously published work}

The use of mobile technology to monitor asthma and other long-term conditions is currently experimental in the UK, and the attitudes of many of our respondents are consistent with those of 'Innovators' and the 'Early Adopters' (see Figure 1) [20]. The patient who wanted to use the technology because it "is available" may be acting as an 'Innovator', while 'Early Adopters' are motivated to adopt it to address an issue of personal importance. For example, several patients identified how the system might help them "manage the situation better" or even "save my life"'. By contrast, the professionals were more guarded in their enthusiasm, recognising that technology didn't necessarily change behaviour and wanting more evidence before concluding that such systems would improve care. This cautious attitude of readiness to consider the advantages is more typical of the 'Early Majority Pragmatists' whose adoption of a new technology is critical to successful widespread acceptance [20].

Practical concerns vive raised about the implications tol pridessional workload and cost to the hatients. Whilst these issues did not appear to dampein the erisuriasm of the 'Innovators' and 'G arly Aciopters', they will need to be fully addressed before mobile technology gains widespread acceptance.

Current asthma guidelines promote selfmanagement [25], and a key strategy for meeting the challenge of long-term diseases is the development of empowered 'expert patients' [26]. It is of some concern, therefore, that both professionals and patients were uncertain about the impact on self-management, and a key benefit for patients was that mobile technology would 'help their doctor or nurse look after their asthma'.

The doctor who was concerned that by accepting the transmission of these peak flow readings she was accepting additional responsibility with incumbent medico-legal risks echoes the recognised professional concerns about liability associated with using innovative technology $[3,27]$. Medical defence organisations currently provide minimal guidance for clinicians on safe practice with mobile technology, effectively discouraging widespread adoption.

Government policy encourages remote consultation as a means of improving access to primary care services [28]. Some respondents were impressed that web-based peak flow records 
could facilitate communication with a clinician during remote consultations, while others were concerned that the technology "may lessen faceto-face contact'". These perspectives echo surveys of patients' preference for alternative modes of consultation which suggest that while many welcome telephone consultations, about a sixth prefer the reassurance of face-to-face contact $[3,29]$.

\section{Conclusions}

Although greeted with enthusiasm by a significant minority, using mobile technology to monitor asthma raised many important questions for both patients and professionals. Widespread implementation will depend on demonstrating clinical effectiveness, assessing the impact on patients' self-management skills, and addressing important practical concerns about workload, cost and professional liability. Future studies should explore these concerns.

\section{Conflicts of interest}

None known.

\section{Acknowledgments}

We thank the rrat.ifes from the lotiancatol Borders Primary Care Research $N \in$ t Vork, and Kent and Medway Primary Care Researth Network who mailed questionnaires to people on their asthma registers: Mildmay Surgery, Ramsgate; Church Lane Surgery, New Romney; Thames Avenue Surgery, Rainham; Ashgrove Health Centre, Blackburn; McKenzie Medical Practice, Edinburgh; Murieston Medical Practice, Livingston. We also wish to thank colleagues from the Whitstable Medical Practice, and Ms Wendy Halley, from the Edinburgh 'BreatheEasy' group who piloted and offered advice on the questionnaire design. Lastly, we record our appreciation to Alison Tait who undertook the mailing of the questionnaires and data entry.

HP led the development of the protocol, securing of funding, study administration, data analysis, interpretation of results and writing of the paper. RS undertook the data collection and data analysis, and with AS, CP and DP contributed to the securing of funding, interpretation of data and the writing of the paper. All authors reviewed the final manuscript. HP and RS are study guarantors.

Funding: British Lung Foundation Grant no. 02-02.

\section{References}

[1] Car J, Sheikh A. Telephone consultations. BMJ 2003;326:966-9.

[2] Car J, Sheikh A. Email consultations 1: scope and effectiveness. BMJ 2004;329:435-8.

[3] Car J, Sheikh A. Email consultations 2: scope, acceptability and safe application. BMJ 2004;329:329-42.

[4] McKinstry B, Walker J, Campbell C, Heaney D, Wyke S. Telephone consultations to manage requests for same-day appointments: a randomised controlled trial in two general practices. Br J Gen Pract 2002;52:306-10.

[5] Thompson F, George S, Lattimer V. Overnight calls in primary care: randomised controlled trial of management using nurse telephone consultation. BMJ 1999;319:1408.

[6] Pinnock H, Bawden R, Proctor S, et al. Accessibility: acceptability and effectiveness of telephone reviews for asthma in primary care: randomised controlled trial. BMJ 2003;326:477-9.

[7] Franklin V, Waller A, Pagliari C, Greene S. "Sweet Talk": Text Messaging Support for Intensive Insulin Therapy for Young People with Diabetes. Diabetes Technology \& Therapeutics 2003;5(6):991-6.

[8] Vodafone Mori. The British mobile communications survey. London: Vodafone; 2003.

[9] Pal B. The doctor will text you now: is there a role for the mobile telephone in healthcare? BMJ 2003;326:607.

[10] Neville RG, Greene A, McLeod J, Tracy A, Surie J. Mobile phone text messaging can help young people manage asthma. BMJ 2002;325:600.

[11] Powell H, Gibson FC. Oppior s for self-management eduraticn for acuts with asthma. The Cochrane Da anase of Systematic Reviews 2002;(3), doi:10.1002/14551918 CD004107. Art. No.: CD004107.

[12] Greap A, Pas, icrie, Mukhopadhay S, Alexander V, Howells Ioville R, et al. Health Beliefs, behaviour and goals of professional carers and adolescents with asthma: exploring and matching perspectives for improving concordance with self-management. Final Report. NHS National R\&D Programme on Asthma Management. 2003.

[13] Yorke J, Fleming SL, Shuldham CM. Psychological interventions for adults with asthma. The Cochrane Database of Systematic Reviews 2006;(1), doi:10.1002/14651858.CD002982.pub3. Art. No.: CD002982.pub3.

[14] Klein JJ, van der Palen J, van den Hof S, Rovers MM. Selftreatment by adults during slow-onset exacerbations of asthma. Patient Ed Counsel 1997;32:S61-6.

[15] Gibson PG, Toneguzzi RC. Self-management: autonomy and Quality of Life in Asthma. Chest 1995;107:1003-8.

[16] Pinnock HJ, Johnson A, Young P, Martin N, Walters P. Acute asthma attacks: the patient's perspective. Asthma J 2000;5:130-2.

[17] Fleming SL, Pagliari C, Churchill R, McKean M, Shuldham CM. Psychotherapeutic interventions for adults with asthma. The Cochrane Database of Systematic Reviews 2003;(4). Art. No.: CD002982.

[18] Ryan D, Cobern W, Wheeler J, Price D, Tarassenko L. Mobile phone technology in the management of asthma. J Telemed Telecare 2005;11(S1):43-6.

[19] Rogers E. Diffusion of Innovations. Simon \& Schuster; 1995.

[20] Moore GA. Crossing the Chasm. New York: HarperBusiness; 1991.

[21] Boynton PM, Greenhalgh T. Selecting, designing and developing your questionnaire. BMJ 2004;328:1312-5.

[22] Boynton PM. Administering, analysing, and reporting your questionnaire. BMJ 2004;328:1372-5. 
[23] Bryman A. Qualitative data analysis. In: Social Research Methods. Oxford: Oxford University Press; 2001. p. 381-403.

[24] Tashakkori A, Teddlie C. Mixed Methodology: Combining Qualitative and Quantitative Approaches. California: Sage Publications; 1998.

[25] The British Thoracic Society/Scottish Intercollegiate Guideline Network. British Guideline on the management of asthma. Thorax 2003;58(S1):i1-i94.

[26] Department of Health. The Expert Patient: A new approach to chronic disease management for the 21st century. London: Department of Health; 2001.
[27] Pagliari C, Gregor P, Sloan D, et al. Literature Review and Conceptual Map of the Field of eHealth. 2005 NHS Service Delivery and Organisation Programme. http://www.sdo.lshtm.ac.uk/ehealth.htm\#pagliari.

[28] Department of Health. Building on the best: choice, responsiveness and equity in the NHS. London: DoH; 2003.

[29] Pinnock H, Madden V, Snellgrove C, Sheikh A. Telephone or surgery asthma reviews? Preferences of participants in a primary care randomised controlled trial. Prim Care Respir J 2005;14:42-6.

Available online at www.sciencedirect.com

\section{$\because$ ScienceDirect}

\section{Available online at http://www.thepcrj.com}

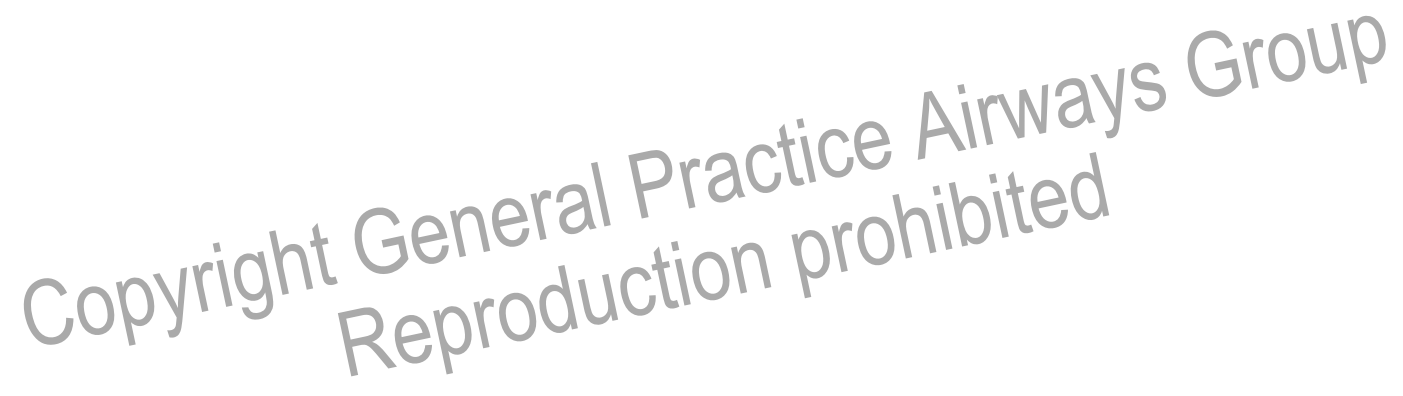

